\title{
UNHEARD VOICES
}

\section{The Consultant Anaesthetist}

\section{[From a SPECIAL CORRESPONDENT]}

"Although I sometimes hanker for my native Cheviots," said Dr. Cadwallader, the anaesthetist, "I've come to like this apparently dull part of the Midlands-this part of the world that Hilaire Belloc said should be traversed only in a sleeping car. Besides I've got too good a set-up here ever to want to move; I'm in administrative charge of a first-rate team of consultant and junior staff, and I particularly value my links with the university academic department of anaesthesia, only ten miles away up the motorway."

Now aged 41, Dr. Cadwallader has been a consultant for nine years. Four years ago he took administrative charge of the anaesthetic services for the three hospitals in his group, and now has a team of five consultants, one senior registrar, three registrars, and two senior house officers. All of the consultants are young and all have maximum part-time appointments. The quality of the junior staff, Dr. Cadwallader says, is generally excellent, the posts being filled by doctors who have already done other junior appointments at the hospitals or by applicants from the local university hospitals. Most of the senior house officers are trying to get the Primary Fellowship of the Faculty of Anaesthetists, and are usually able to spend four mornings a week at the local university on a special basic sciences course. The registrars, usually having passed the Primary examination, concentrate on working for the Final, which they almost invariably pass"then," said Dr. Cadwallader ruefully, "retreat almost overnight into the teaching hospitals." Even so, he is sure that it is this kind of record that keeps the quality of the junior staff at its persistently high level.

\section{Happy, and not Stressed}

Questioned about his work, Dr. Cadwallader emphasized that he was happy and not stressed. On an average day he arrived at his hospital at 8.30 and was home in the evening by 7.30. The excellent rota system among the junior staff ensured that he was rarely called to the operating theatre at nightthough he was frequently consulted by telephone-but when on duty he was first on call for patients on intensive care. Quite a lot of his time was spent on postgraduate education; he was tutor for the local postgraduate medical centre, and, besides organizing general courses of continuing education for the hospital staff and local general practitioners, together with his anaesthetic colleagues he also arranged vocational training in anaesthesia for his junior staff. He spent roughly two hours a week in committees, either at the hospital or at the regional hospital board. At the weekends he often gave anaesthetics to private patients; being a prosperous area, the demand for private practice was considerable, and all the consultant anaesthetists augmented their incomes in this way.

I then asked Cadwallader about his frustrations. Did he, for instance, think the committees achieved anything? Unlike Alde, ${ }^{1}$ he was convinced that committees were worthwhileor, rather, he could miss something important if he did not attend. "But," he went on, "what is frustrating is that my work-load doesn't allow me to get down to London enough. Many of the decisions that matter to my department are taken not at the regional hospital board, nor in the university department, but at the Faculty of Anaesthetists in London. By being unable to get there (unlike one's teaching hospital colleagues) I feel I'm missing out-both intellectually and politically, about the whole future of the specialty. There is no doubt," Cadwallader continued, "the National Health Service has virtually encouraged the full development of the specialty of anaesthesia throughout this country, and our standards are the highest in the world. I'm sure this is due to two things-the 'ladder' system and a specialist degree with a high standard. Both of these have ensured that we recruit doctors of the highest intellectual calibre to anaesthesia, and also that consultants in all specialties are roughly of the same intellectual standard. If the Godber report comes into operation, these standards are certain to decline and we shall probably look back on the present as the golden age of British anaesthesia. To me the implications in this report that we can shorten the length of training period, possibly do without higher degrees, and that anybody who starts the specialty will end up as a fully fledged consultant, are nonsense. There must be competition, and people must be pushed off the ladder if they can't make the grade. Also, the two or three year period spent as a senior registrar is one of the most valuable times in an anaesthetist's career, for, freed of many of the pressures of routine work and preparing for examinations, he has time to consolidate and study his subject in depth."

\section{Future Staffing Structure}

But what about the future staffing structure, I asked. Cadwallader pointed out that if a ladder system was kept in some form, it would mean that there would be more junior posts than were proposed by Godber. Also an excess of junior posts was necessary to accommodate those who had not made up their minds about what specialty to go in for, and those who were intending to enter general practice after various hospital posts. "But it may be," he went on, "that the Godber report is compatible with adequate junior staffing in the periphery if one important change is made-that is, that there must be compulsory rotation between the teaching and the district hospitals. We all know the arguments for the large staffs at teaching hospitals-they have to do research, teach, be centres of excellence, and so on. But equally we all know that there are many juniors who are short of practical experience; it's these we must get into the periphery, and I'm sure they'd welcome the opportunity to do a proper workload there if they were guaranteed a return trip to their teaching hospital."

Cadwallader was adamant in rejecting my suggestion that part-time help from general practitioners or married women could have a useful role. Part-time clinical assistants could never be part of an anaesthetic team; one would rarely see them, and they tended to develop fixed ideas, which were often rooted in the past. "You might think that they could come in to do the minor casualties or the minor ops list; in fact, these constitute some of the most dangerous anaesthetics to give and really require a consultant or a whole-time trainee to administer them."

\section{Two Main Grouses}

There was no doubt that Dr. Cadwallader enjoyed his job, and was doing what he wanted in his own way. The theatre suites were modern and he had excellent support from nurses and theatre technicians. All things considered, he had only two main grouses. The first was his facilities for intensive care. For the past six years he had been trying to get permission to build a four-bedded intensive care unit. Besides replacing the poorly adapted side-rooms scattered among the three hospitals by a purpose-built modern unit at one of them, this would enable him to train a team of nurses, thereby improving the standard of care. But to his yearly request to the regional hospital board there had been a different reply 
every time; once simply "no"; once "approved in theory, but no money left"; once "the architect has some detailed criticisms of your plans." So what should he do-press on or give up? This was another tangible example of how remote he felt from the centre of power.

Cadwallader's second grouse was pay. He had no merit award and did not expect one at any stage in his career, pointing out that, of all the specialties, anaesthesia had one of the lowest percentages of awards. "We can't, of course," he said, "make this up with domiciliary visits, so we have to bolster up our earnings from $9 / 11$ sessions by doing private practice. It's not generally realized how much this restricts one's mobility-you must be around if the surgeon wants you, and much of his private work is done at the weekend.
So I think we're badly off compared with some other specialties, and particularly general practice, where a man may start at $£ 3,500$ a year when he's 27 . This could be remedied in several ways, but certainly the sessional fee should be considerably increased so that the newly appointed maximum part-time consultant could at least earn as much as an assistant in general practice. Finally, the number of increments in a consultant's career should be cut. I've never understood why there should be this gradual system of working one's way up to the top. There should just be two salary levels-the first when a man's just got his consultant post, the second after. three years when he's a truly valuable member of the team."

1 British Medical fournal, 1970, 1, 492.

\section{ONE HUNDRED YEARS AGO}

\section{Leading Article from the British Medical fournal 2 April, 1870 LADY SURGEONS}

We observe that not a few of the writers of the day are beginning to assume that it is proved that women may suitably pursue the medical profession. The facts that a few ladies have obtained diplomas and are now engaged in practice, and that a somewhat larger number are at present occupied in medical studies, seem to be considered conclusive. For our part we cannot think so. Surely a much longer experiment and one too on a far larger scale, is desirable before we admit that such an important social innovation is a success. The subject has, however, certainly assumed proportions which render it worthy of careful investigation. It is most desirable, in approaching it, to avoid if possible the prejudices which custom has reared, and to think, if we can, as our descendants may not improbably think when they have had fifty years' additional experience. It may be that in half a century a fair proportion of the medical profession will be of the female sex, and that the more advanced opinions of the community will smile at the bygone scruples which held it an indelicate thing for young ladies to mix with other students in the dissection-room and lecture-theatre. Whatever the verdict of the future may be, however, whether it may confirm or reverse the opinions of the past, we by no means admit that it will be conclusive as to the right or wrong, the wisdom or unwisdom, of the change. In this respect it will be but little less open to risks of error than are the opinions of the present; and it is quite possible that, should the change which we have suggested come about, it may prove a matter of sincere regret to all capable of really appreciating its results. ...

To us, looking on from a distance on such social experiments as those to which we have referred, it appears very clear that, excepting on the theory that celibacy is either desirable, or at any rate unavoidable, it is impossible to believe that any benefit can accrue to the female sex as a whole by opening to it the means of livelihood which men have hitherto exclusively enjoyed. If society has really come to such a pass that the pursuits which have hitherto enabled men to gain a living for themselves, their wives and families, no longer do so, and that our young men are obliged to remain single and appropriate to themselves all they can earn, let us by all means fully acknowledge the fact and its consequences. If it has really come to a game of sauve qui peut, then let every one have a fair chance in the scramble. Under such circumstances it would be unfair to impose social disabilities on either sex. Rather, in the name of justice, let both fight together on equal terms, for such fragments of happiness as may be yet secured. There are some, we believe, who, having looked carefully into our social tendencies, honestly believe that increasing celibacy is inevitable, and who are, therefore, according to our argument, fairly entitled to urge the right of the female sex to independent employments. To those who have not yet adopted this very serious creed, we would address an earnest request that they will take the trouble to estimate the kind of effect in that direction which the introduction of female workers into male vocations must inevitably have. That effect will, in the long run, be to increase celibacy by reducing the emoluments of the male sex, and will most certainly give us year by year a greater and greater number of ladies who will need independent means of support. The lady-doctor is, therefore, as we take it, unless she be conscientiously an advocate of celibacy, a traitress to her sex. She betrays their real interests to her own eccentric longing for the will-o'-the-wisp pleasures of independence. In the olden time, it was thought most fitting that boys should climb the apple-trees and share the proceeds with the girls. Now that apples are becoming scarce, there seems to be a growing impression that the boys keep the best for themselves. Without giving any opinion as to whether or not this complaint is well grounded, we may be permitted to urge that there are two ways out of the difficulty. It is noi even yet absolutely necessary that the girls should climb themselves; they might possibly attain quite as much by seeking to develope in their brothers and cousins a more energetic spirit of daring, and a better notion of chivalry and honour. It will be a bitter lesson to most of us if ever we are forced to learn it, that the interests of the sexes are not absolutely identical-that they may, indeed, be competitive or antagonistic. The judicious division of labour is among the chief gains of civilisation and means of advance, and first under that head we have hitherto ranked the appropriation of suitable tasks in life to the two sexes. The exemption of the female sex from all pursuits involving hard labour, is a feature which characterises all communities which make any pretence to social development. Our object of the present is not so much to show that the pursuit of medicine is intrinsically inappropriate to women, as to prove that there could be no real advantage to the sex in allowing them to pursue it, and that, on the contrary, such permission would tend to increase the very evils under which society now suffers. Our assertion is, that society is at present much in the position of the host who had thirteen guests and only twelve chairs for them. It must be evident that such a difficulty could not be solved by any system of exchange of places, and most will admit that to let the guests fight it out, and leave the defeated one to stand, would be a very rude expedient. The only reasonable solution of such a difficulty is to procure another chair; and, with precisely like confidence, it may be asserted that the only true solution of the present defective supply of the means of human happiness is to take measures to augment it. Mere readjustment will do nothing. That there is an inexhaustible supply at hand, if only we could develope the energy necessary to secure it, we firmly believe. 